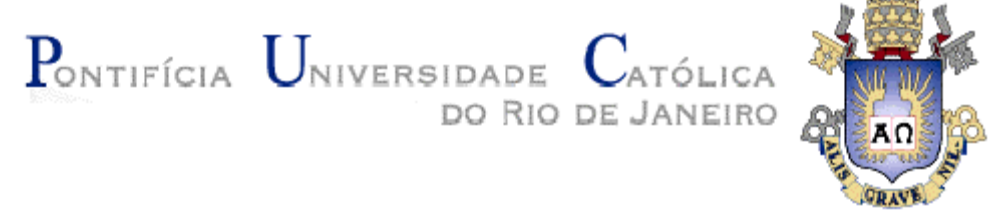

Maria Isabel Ramalho Ortigão

\title{
CURRÍCULO DE MATEMÁTICA E DESIGUALDADES EDUCACIONAIS
}

\section{Tese de Doutorado}

Tese apresentada ao Programa de Pósgraduação em Educação do Departamento de Educação da PUC-Rio como parte dos requisitos parciais para obtenção do título de Doutor em Educação.

Orientador: Creso Franco

Co-orientador: João Bosco Pitombeira de Carvalho 
Maria Isabel Ramalho Ortigão

\title{
CURRÍCULO DE MATEMÁTICA E DESIGUALDADES EDUCACIONAIS
}

Tese apresentada como requisito parcial para obtenção do grau de Doutor pelo Programa de Pós-Graduação em Educação do Departamento de Educação do Centro de Teologia e Ciências Humanas da PUC-Rio. Aprovada pela Comissão Examinadora abaixo assinada.

\author{
Prof. Creso Franco \\ Orientador \\ Departamento de Educação - PUC-Rio \\ Prof. João Bosco Pitombeira de Carvalho \\ Co-Orientador \\ Departamento de Educação - PUC-Rio \\ Prof.José Carmello Braz de Carvalho \\ Departamento de Educação - PUC-Rio \\ Prof. Elizabeth Belfort da Silva Moren \\ UFRJ \\ Prof. Paulo Figueiredo Lima \\ UFPE \\ Prof. Celso José da Costa \\ UFF \\ Prof. Paulo Fernando C. de Andrade \\ Coordenador Setorial do Centro de \\ Teologia e Ciências Humanas
}

Rio de Janeiro, 05 de agosto de 2005 
Todos os direitos reservados. É proibida a reprodução total ou parcial do trabalho sem autorização da universidade, doa autora e do orientador.

\section{Maria Isabel Ramalho Ortigão}

Mestre em Educação pela PUC-Rio em 1999. Desde 2001 é pesquisadora assistente do Laboratório de Avaliação da Educação (LAED/PUC-Rio) e coordenadora adjunta do Curso de Especialização em Educação Matemática: Teoria e Prática Pedagógica da PUC-Rio. De 2000 a 2003 lecionou a disciplina Metodologia do Ensino da Matemática no Departamento de Educação da PUC-Rio. De 1980 a 2001 lecionou Matemática em escolas de Ensino Fundamental e Médio. Neste período atuou na formação continuada de professores de Matemática da educação básica. É co-autora de artigos na área de educação e de materiais didáticos da Fundação Roberto Marinho, tais como Telecurso 2000/Matemática e Multicurso Matemática.

Ficha catalográfica

Ortigão, Maria Isabel Ramalho

Currículo de matemática e desigualdades educacionais / Maria Isabel Ramalho Ortigão ; orientador: Creso Franco ; coorientador: João Bosco Pitombeira de Carvalho . - Rio de Janeiro : PUC-Rio, Departamento de Educação, 2005.

174 f. $; 30 \mathrm{~cm}$

Tese (doutorado) - Pontifícia Universidade Católica do Rio de Janeiro, Departamento de Educação .

Inclui referências bibliográficas

1. Educação - Teses. 2. Currículo. 3. Desigualdade educacional. 4. Ensino de matemática. 5. Seleção de conteúdos. 6. Matemáticos. I. Franco, Creso. II. Carvalho, João Bosco Pitombeira. III. Pontifícia Universidade Católica do Rio de Janeiro. Departamento de Educação . III. Título. 
Aos professores que acreditam em uma educação de qualidade para todos. 


\section{Agradecimentos}

Ao Creso Franco, pela orientação, confiança e incentivo presentes nas discussões teóricas e na viabilização da pesquisa.

Ao Pitombeira, pela orientação no campo da Educação Matemática, pelas sugestões bibliográficas e conversas elucidativas.

À Sibele, parceira nos 5.000 quilômetros rodados durante o trabalho de campo.

À Mônica Mandarino pela longa amizade e o caminho percorrido juntas na Educação Matemática.

À Ângela, Glauco, Fátima e aos colegas de curso e do grupo de pesquisa, por compartilharem as suas experiências.

A todos os professores do Programa de Pós-graduação em Educação da PUC-Rio, que direta ou indiretamente contribuíram para este trabalho.

Aos funcionários do Departamento de Educação pela presteza na resolução dos aspectos operacionais do trabalho.

À Secretaria Municipal de Educação pelas informações disponibilizadas para a pesquisa.

Aos Diretores, Coordenadores e Professores das escolas pesquisadas, que abriram as portas para que o trabalho fosse realizado.

À CAPES, pelo apoio financeiro, sem o qual este trabalho não seria possível.

Ao Octacílio pelo companheirismo e compreensão em todos os momentos. 


\section{Resumo}

Ortigão, Maria Isabel Ramalho; Franco, Creso; Pitombeira, João Bosco. Currículo de Matemática e Desigualdades Educacionais. Rio de Janeiro, 2005. 174p. Tese de Doutorado - Departamento de Educação, Pontifícia Universidade Católica do Rio de Janeiro.

Este trabalho investiga o currículo de Matemática do Ensino Fundamental $\left(5^{\mathrm{a}}\right.$ a $8^{\mathrm{a}}$ séries $)$ em relação aos conteúdos ensinados e às práticas pedagógicas adotadas pelos docentes. Partindo do princípio de que os conteúdos são previamente selecionados pelo professor e abordados nas aulas com ênfases diferenciadas, esta pesquisa busca responder três questões: (a) que conteúdos de Matemática são selecionados para o ensino de $5^{\mathrm{a}}$ a $8^{\mathrm{a}}$ série? (b) a seleção de conteúdos matemáticos é influenciada pelo perfil socioeconômico da clientela da escola?; (c) quais características da prática pedagógica são associadas com a seleção de conteúdos matemáticos. Para a realização do estudo, um questionário auto-administrado foi submetido a 168 professores que lecionam Matemática no Ensino Fundamental, em uma amostra probabilística de 48 escolas municipais e particulares situadas na cidade do Rio de Janeiro. O instrumento consistiu de 79 itens e buscou investigar as afirmações dos docentes sobre suas práticas pedagógicas em Matemática, e sobre a organização da sala de aula. Adicionalmente, foram incluídas perguntas que ajudassem a traçar um perfil dos professores. A opção desta pesquisa foi por obter uma visão geral e ampliada do ensino de Matemática. Neste sentido, olhamos mais de longe para um grupo ampliado, ao invés de olhar bem de perto para um caso pontual. A análise dos dados coletados foi baseada na aplicação de um modelo de regressão. Os resultados indicam que a seleção e a abordagem de conteúdos matemáticos são fortemente condicionadas por características do perfil socioeconômico médio dos estudantes das escolas. Neste sentido, alunos de menor poder aquisitivo são os que menos freqüentemente lidam com Tratamento da Informação. Entretanto, quando o professor afirma adotar livro didático em sala, os alunos têm maior chance de lidarem com estes temas. Na rede pública, características como uso de jogos e quebra-cabeças e ênfase em resolução de problemas são fatores associados ao aumento na chance de seleção de conteúdos matemáticos. Estas características não influenciam a seleção em escolas da rede particular.

\section{Palavras-chave}

Currículo, Desigualdade educacional, Ensino de matemática, Seleção de conteúdos matemáticos. 


\section{Abstract}

Ortigão, Maria Isabel Ramalho; Franco, Creso; Pitombeira, João Bosco (Advisors). Math Curriculum and Educational Differences. Rio de Janeiro, 2005. 174p. Tese de Doutorado - Departamento de Educação, Pontifícia Universidade Católica do Rio de Janeiro.

This work investigated the curriculum of Mathematics applied to middle school in Brazil, grades $5^{\text {th }}$ to $8^{\text {th }}$, in regards to taught subjects and to teaching approaches used by faculty. From the premise that taught subjects are previously selected by teachers and applied in the classroom using different emphasis, our work aimed at answering three basic questions: 1) what are the Math subjects selected for the grades $5^{\text {th }}$ through $8^{\text {th }} ; 2$ ) Is the selection of Math subjects influenced by the socio-economical profile of the students within a school; 3) what teaching characteristics are associated with the selection of Math subjects. For this study, a self-administered questionnaire was submitted to 168 middle school teachers, comprising 48 public and private schools within the City of Rio de Janeiro. The questionnaire consisted of 79 items and sought to evaluate the responses from faculty regarding their teaching practices in relation to taught subjects, teaching approach and classroom organization. Additionally, questions that could help us draw a profile of different faculty were also added. The goal of this investigation was to obtain a generalized and ample view of the teaching of Mathematics, as the analysis was based not on a single isolated case but instead on a larger, more separate group. Analysis of data obtained was based on the application of a regression model. The results indicated that selection and teaching approach of math subjects are strongly influenced by the average socio-economic profile of students at a given school. We also observed that the characteristics associated with the selection of math subjects are not equal when we compared the two different school systems.

\section{Key words}

Curriculum, teaching of mathematics, selection of math subjects 


\section{Sumário}

1. Educação e desigualdades sociais: apresentando a pesquisa

2. O currículo e os mecanismos de produção de desigualdades educacional

2.1. Qualidade da educação ....................................................... 23

2.2. Currículo .................................................................... 32

2.3. Currículo e ensino de matemática: a proposta de renovação dos anos 1990, ainda vigente

2.4. Pesquisas sobre o efeito das reformas do ensino de matemática 38

3. Método

3.1. O quadro de referência conceitual .......................................... 46

3.2. A construção do questionário .................................................. 53

3.2.1. Facilitar a entrada de dados ........................................ 53

3.2.2. Tornar os itens claros ................................................. 54

3.2.3. Ordenamento dos itens no questionário ........................ 54

3.2.4. Formato geral dos questionários ................................. 55

3.3. Procedimentos iniciais de validação ………............................ 55

3.4. A coleta de dados ....................................................... 58

3.4.1. A seleção da amostra ................................................ 59

3.4.2. O trabalho de campo ................................................. 62

3.4.3. Apresentação das pesquisas para as escolas ................. 63

3.4.4. Aplicação dos questionários ....................................... 64

3.5. Procedimentos adicionais de validação empíricos .................... 66

3.5.1. Validação por construção ............................................ 66

3.5.2. Validação por triangulação .......................................... 76

3.6. Abordagem analítica ...................................................... 80 
4. A distribuição social do currículo: análise exploratória ......................... 84

4.1. As escolas .................................................................. 84

4.2. Práticas Pedagógicas em Matemática ………......................... 90

4.3. A seleção de conteúdos para o ensino .................................... 97

4.3.1. Os conteúdos selecionados para o ensino de Matemática ....... 101

4.4. A distribuição dos conteúdos ............................................... 106

4.5. Seleção de conteúdos relativos a "Tratamento da Informação": um estudo exploratório

5. A distribuição social do currículo: modelagem

5.1. Modelo de regressão para a seleção de conteúdos relacionados com Tratamento da informação

5.2. Resultados do modelo de regressão para a seleção de conteúdos relativos à Tratamento da informação - rede privada

5.3. Resultados do modelo de regressão para a seleção de conteúdos relativos à Tratamento da informação - rede municipal

5.4. Resultados do modelo de regressão logística ordinal para a abordagem de conteúdos relativos à "Tratamento de Informação"

6. Considerações finais 


\section{Lista de Figuras, quadros, gráficos e tabelas}

\section{Lista de figuras}

Figura 1: Esquema da operacionalização de conceitos latentes 43

Figura 2: Planejamento geral da pesquisa

Figura 3: Mapa da cidade do Rio de Janeiro com a indicação das escolas da Amostra

\section{Lista de Quadros}

Quadro 1: Estágios e competências de desempenho do SAEB e o percentual de alunos de 8a série do Ensino Fundamental em cada estágio

Quadro 2: Onze características encontradas em Escolas Eficazes, de acordo com Sammons, Hillman e Mortimore

Quadro 3: Conceitos propostos por Willms para a avaliação de sistemas Escolares 28

Quadro 4: Quadro-resumo dos conceitos e suas classificações, por tema 47

Quadro 5: Quadro-resumo dos conceitos e suas especificações em relação ao tema conteúdos de Matemática

Quadro 6: Quadro-resumo dos conceitos, suas especificações e itens, em relação ao tema abordagem didática

Quadro 7: Quadro-resumo dos conceitos, suas especificações e itens, em relação ao conceito latente "ênfase em trabalho conjunto"

Quadro 8: Quadro-resumo dos conceitos, suas especificações e itens, em relação ao tema tratamento do conteúdo

Quadro 9: Quadro-resumo das escalas 68

Quadro 10: Quadro-resumo das turmas e séries observadas de cada professor. 79

Quadro 11: Síntese dos conteúdos selecionados pelos docentes para o ensino em suas aulas 102

Quadro 12: Variáveis utilizadas nos modelos de regressão logística 133 


\section{Lista de gráficos}

Gráfico 1: Evolução da Taxa de Escolarização Líquida da população brasileira no EF

Gráfico 2: Evolução das médias em Matemática - 8a série: Brasil e Redes

Gráfico 3: Escolas selecionadas para a sub-amostra, em relação à rede de ensino e nível socioeconômico médio dos alunos

Gráfico 4: Distribuição das escolas segundo o nível socioeconômico médio dos alunos da escola, por rede e tipologia

Gráfico 5: Distribuição dos professores segundo ênfase em resolução de problemas e nível socioeconômico da escola, por rede e tipologia ....

Gráfico 6: Distribuição dos professores segundo ênfase em automatização e nível socioeconômico médio dos alunos da escola, por rede e tipologia

Gráfico 7: Distribuição dos professores segundo ênfase em trabalho conjunto e nível socioeconômico médio dos alunos da escola, por rede e tipologia

Gráfico 8: Distribuição dos professores segundo ênfase em trabalho resolução de problemas e nível socioeconômico médio dos alunos da escola, por rede

Gráfico 9: Proporção de professores que afirmam selecionar conteúdos relacionados a Números e operações, segundo o NSE médio dos alunos da escola

Gráfico 10: Proporção de professores que afirmam selecionar conteúdos relacionados a Geometria, segundo o NSE médio dos alunos da escola

Gráfico 11: Proporção de professores que afirmam selecionar conteúdos relacionados a Álgebra, segundo o NSE médio dos alunos da escola

Gráfico 12: Proporção de professores que afirmam selecionar conteúdos relacionados a Medidas e grandezas, segundo o NSE médio dos alunos da escola

Gráfico 13: Proporção de professores que afirmam selecionar conteúdos relacionados a Tratamento da Informação, segundo o NSE médio dos alunos da escola

Gráfico 14: Distribuição das escolas da amostra segundo o nível socioeconômico médio de seus alunos, por rede 


\section{Lista de Tabelas}

Tabela 1: Número de escolas, professores, turmas e alunos da amostra 60

Tabela 2: Porcentagem de respostas segundo ênfase em resolução de

Problemas

Tabela 3: Média e Coeficiente de Loevinger para os itens relacionados à ênfase em resolução de problemas 70

Tabela 4: Porcentagem de respostas segundo ênfase automatização 71

Tabela 5: Média e Coeficiente de Loevinger para os itens relacionados à ênfase em automatização

Tabela 6: Porcentagem de respostas segundo ênfase em trabalho conjunto 72

Tabela 7: Média e Coeficiente de Loevinger para os itens relacionados à ênfase em trabalho conjunto 73

Tabela 8: Percentual de resposta segundo a escolaridade familiar 74

Tabela 9: Porcentagem de respostas segundo a posse de bens familiar 74

Tabela 10: Média e Coeficiente de Loevinger para os itens relacionados à posse de bens familiar

Tabela 11: Porcentagem de respostas segundo a disponibilidade de recursos educacionais/culturais familiar

Tabela 12: Média e Coeficiente de Loevinger para os itens relacionados à disponibilidade de recursos educacionais/culturais familiar 76

Tabela 13: Número médio de alunos, turmas e professores de Matemática nas escolas da amostra, por rede

Tabela 14: Médias e desvios padrões da pontuação obtida pelos professores da amostra em cada escala

Tabela 15: Médias e desvios padrões da pontuação obtida pelos professores da amostra em cada escala, segundo a rede

Tabela 16: Distribuição percentual dos professores ao afirmarem sobre os conteúdos selecionados para o ensino em aulas de Matemática 107

Tabela 17: Percentual de professores que afirmam selecionar "Tratamento da Informação" segundo a dependência administrativa da escola .

Tabela 18: Percentual de professores que afirmam selecionar "Tratamento da Informação" segundo uso de livro didático em sala 
Tabela 19: Percentual de professores que afirmam selecionar "Tratamento da Informação" segundo uso de jogos em sala

Tabela 20: Percentual de professores que afirmam selecionar "Tratamento da Informação" segundo uso de jornais e revistas informativas em sala. 121

Tabela 21: Freqüência com que jornais e revistas são utilizados em sala de aula, de acordo com as respostas dos professores de acordo com a rede em que atua

Tabela 22: Percentual de professores que afirmam selecionar "Tratamento da Informação" segundo ênfase em resolução de problemas

Tabela 23: Percentual de professores que afirmam selecionar "Tratamento da Informação" segundo ênfase em automatização

Tabela 24: Percentual de professores que afirmam selecionar "Tratamento da Informação" segundo ênfase em trabalho conjunto

Tabela 25: Percentual de professores que afirmam selecionar "Tratamento da Informação" segundo tipo de instituição onde se graduou

Tabela 26: Percentual de professores que afirmam selecionar "Tratamento da Informação" segundo continuidade nos estudos

Tabela 27: Percentual de professores que selecionar "Tratamento da Informação" segundo afirmação de que o curso se relaciona com a área de EM

Tabela 28: Percentual de professores que afirmam selecionar "Tratamento da Informação" segundo participação em evento de formação Continuada

Tabela 29: Percentual de professores que afirmam selecionar "Tratamento da Informação" segundo afirmação leituras específicas na área

Tabela 30: Percentual de professores que afirmam selecionar "Tratamento da Informação" segundo leituras de revista de divulgação científica

Tabela 31: Estatísticas descritivas das variáveis utilizadas na modelagem (rede municipal)

Tabela 32: Estatísticas descritivas das variáveis utilizadas na modelagem (rede privada)

Tabela 33: Ajuste dos modelos de regressão às probabilidades de seleção de conteúdos relacionados a Tratamento da Informação na rede privada 
Tabela 34: Ajuste dos modelos de regressão às probabilidades de seleção de conteúdos relacionados a Tratamento da Informação nas escolas municipais

Tabela 35: Parâmetros estimados pelo modelo de chance de seleção de conteúdos relacionados a Tratamento da Informação, para a rede privada

Tabela 36: Parâmetros estimados pelos modelos de chance de seleção de conteúdos relacionados a Tratamento da Informação, para a rede municipal

Tabela 37: Parâmetros estimados pelo modelo de chance de abordagem de conteúdos relacionados a Tratamento da Informação, para a rede privada

Tabela 38: Parâmetros estimados pelos modelos de chance de abordagem de conteúdos relacionados a Tratamento da Informação, para a rede municipal 